\title{
Surfaces
}

\section{INTRODUCTION. GONZO SCHOLARSHIP: POLICING ELECTRONIC JOURNALS}

\section{R. A. Shoaf}

Volume 4, 1994

SUR LA PUBLICATION ÉLECTRONIQUE

ON ELECTRONIC PUBLICATION

URI : https://id.erudit.org/iderudit/1064954ar

DOI : https://doi.org/10.7202/1064954ar

Aller au sommaire du numéro

Éditeur(s)

Les Presses de l’Université de Montréal

ISSN

1188-2492 (imprimé)

1200-5320 (numérique)

Découvrir la revue

Citer ce document

Shoaf, R. (1994). INTRODUCTION. GONZO SCHOLARSHIP: POLICING

ELECTRONIC JOURNALS. Surfaces, 4. https://doi.org/10.7202/1064954ar
Résumé de l'article

Texte d'introduction au séminaire présenté par le Council of Editors of Learned Journals (CELJ) au congrès de la MLA qui a eu lieu à Toronto, en 1993, et dont les actes (numérotés 102,103, etc.) sont publiés par Surfaces dans le présent volume. Le séminaire porte sur l'impact de la publication électronique sur le monde académique. 
Gonzo Scholarship

INTRODUCTION

GONZO SCHOLARSHIP:

POLICING ELECTRONIC JOURNALS

\title{
R.A. Shoaf
}

\begin{abstract}
Introductory remarks at the Council of Editors of Learned Journals (CELJ) panel at the MLA in Toronto (1993) whose proceedings are published by Surfaces as Vol. IV 102, 103, 104, etc.. The participants assess the impact of electronic publishing on the scholarly world.
\end{abstract}

\section{RÉSUMÉ}

Texte d'introduction au séminaire présenté par le Council of Editors of Learned Journals (CELJ) au congrès de la MLA qui a eu lieu à Toronto, en 1993, et dont les actes (numérotés 102, 103, etc.) sont publiés par Surfaces dans le présent volume. Le séminaire porte sur l'impact de la publication électronique sur le monde académique.

Because the next century promises to be a radically different era in academic publishing generally and in journal publishing in particular, the Council of Editors of Learned Journals (CELJ) organized and sponsored a panel on "Gonzo Scholarship" at the 1993 MLA meeting, as an example of the kind of conversation it seeks to promote. That radical difference, of course, will be owing in the main to the computer and to what we should probably begin calling "computeracy" (as we call the culture of books, "literacy"). If we consider the rather remarkable fact that the era of the PC 
(the personal computer) is barely fifteen years old today and look, in that light, at the revolution it has effected, then I think it is easy for us to predict that within the first few decades of the 21st century, even more revolutionary changes will occur at every level of our profession. There is, then, a sense in which all of us are already very far behind. And although we perhaps do not want to embrace the ethos of the current joke in the marketplace, all of us in academic publishing need to wake up to he reality of these dramatic changes, or we might indeed become "roadkill on the information superhighway."

As current president of CELJ for a two-year term, I am interested principally in continuing to move the Council in the direction of computeracy (with minimal gore left bobbing in our wake). It may help at this point to describe one major step we have taken in this direction, since it places the panel on "Gonzo Scholarship" in a broader perspective. In 1993 I began establishing an electronic bulletin board or "list-serv" for the membership of CELJ (EDITOR-L). This "list-serv" was up and running by the autumn of 1993, and as of this writing nearly $20 \%$ of the membership have subscribed. My goal in my tenure as president of CELJ is to bring at least $50 \%$ of the membership on-line in EDITOR-L. The benefits of this electronic bulletin board to the membership are obvious: rapid and extensive communication about editorial problems and issues is easy and convenient through the Internet; the exchange of technical information and the negotiation of professional issues among interested parties in academic publishing are immensely facilitated by the speed and the reach of the Internet. At the same time the Internet is still somewhat mysterious if not, in fact, forbidding to academics, and it is significant that in my tenure as president I expect to bring on-line only $50 \%$ of the membership of the Council.

Here indeed is one of the principal motives behind "Gonzo Scholarship," even as it is also a principal reason for the success of that program -namely, the threshold for use of the Internet is still extraordinarily high for a great many academics, especially academics who edit journals, and the desire for more knowledge is keen if also, in many cases, ambivalent. There are fears both vague and (in some cases) precise that the Internet will prove the undoing and elimination of many journals. It is my opinion, privately as well as in my official capacity as President of CELJ, that most of these fears are unfounded; they are misdirected energy. Indeed, many journals may modify their formats, and some journals may even abandon the paper format.

Abandoning this format, however, is not the same thing as disappearing from the scene. To the contrary, in many cases, it may mean precisely the survival and indeed the rejuvenation of a particular journal. However, before any of that may come to pass, more education is needed. Only more education can begin to allay the anxieties and fears the Internet still inspires in many. 
Hence, my colleagues and I in the Executive Committee of CELJ, especially John C. Coldewey, immediate past President, were keenly interested in bringing together the excellent speakers on our panel -- Ann Okerson of the Association of Research Libraries, James O'Donnell of the Classics Department at Penn, and Bill Readings of the University of Montreal, editor of Surfaces. All three of them brought to our panel, in addition to their scholarly and other professional credentials, a clear understanding of the scope and possibilities of the Internet. This understanding included, itis clear from their remarks, a sense of how many of us feel threatened or intimidated by the Internet, too. All three of our speakers addressed both the promises and the threats of electronic publishing and the Internet. It is this, I think, that attracted and maintained the interest of our audience. (It is fitting here to mention that our room was full and no one left until the hour had elapsed. Moreover, it is noteworthy that "Gonzo Scholarship" received extensive coverage in the "Style" section of the Washington Post (30 December 1993) in an article entitled "Scholars Ponder the Cyberspace Chalkboard," by Charles Trueheart). And I think you will see in the essays themselves that Ann Okerson, James O'Donnell, and Bill Readings provided our audience with much to -- well - -- process.

Each of the three papers you are about to read contains data important for understanding the radical impact of the Internet. At the same time, each of the papers is the work of someone who has thought long and hard about the intellectual and emotional consequences of the transformations taking place all around us, as well as their professional implications. They present the Internet with a human face, as William Blake might have put it. Each of them understands how difficult it is to let go of a past that has been commodious and accommodating. Each of them, however, also understands that the future offers a system, a technology, and a related promise that will greatly exceed those benefits of the past, if we begin now to understand and shape them. If in their predictions about the future changes in our profession, they are sometimes sharply pessimistic because we have been slow to seize the initiative, they are nonetheless not corrosively dismissive. Especially in the case of James O'Donnell's paper, there is a keen historical and historicized sense of the kind of transition we are facing. It is the great merit of O'Donnell's contribution that he can analogize so clearly and helpfully between the transition from literacy to computeracy and the transition from manuscripts to print literacy five hundred years ago. The analogies are extraordinarily helpful in thinking through the implications of the changes confronting us.

More sharply critical of the status quo of current academic publishing, and journal publishing in particular (?), Bill Readings offers some acerbic comments on the current situation, but only, I think, to spur us to be atoncemore open and more adventurous -- which clearly we must be, given the speed and scope of such changes as Ann Okerson outlines in her paper. Thus, for example, to take just one point that Readings makes: in the world of Internet publishing, length is no longer a valid criterion for rejecting an item of work. Similarly, related to the issue of length, a work need never be 
"finished" again (works, of course, are never finished anyway, simply abandoned). Any work canbe updated, revised, expanded, altered, corrected indefinitely, because of its electronic form and availability through the Internet. These are radical changes if one stops to consider the criteria used in the past for judging what does and does not go into a journal. To be sure, these possibilities will be perceived as threatening by many, and certainly there is room in these developments for "unpoliced" publication. But that may not be such a bad thing. To the contrary, these developments can clearly be liberating. After all, we have long since passed the condition of publishing or perishing; as individuals and as journals, we too often these days publish and perish anyway. We need to change not just what we publish, then, but the way we publish and the way we think about publishing. We need to do this not only to meet the new and wholly correct emphasis on teaching and educating our youth, for giving them guidance, for equipping them for the rapidly changing world, etc. We need to do this also, and just as urgently, to make sense out of our own profession -- to preserve what is best in our profession and to correct what needs correcting in it.

Following the success of "Gonzo Scholarship" at the 1993 MLA meeting, CELJ will sponsor a related panel at the 1994 meeting in San Diego, tentatively entitled "Refereeing : Gatekeeping -- The Question of Legitimation in Academic Publishing." This panel will closely follow the lead of a similar panel at the 1993 South Atlantic Modern Language Association Meeting (Atlanta, 5-7 November). Two member editors of CELJ, Mark Winchell and Eugene Hollahan, formed a panel for SAMLA on the necessity of refereeing journal articles. I was fortunate enough to have been able to attend that panel, and was very impressed. The turn-out was large, and the degree of commitment and engagement of both panel and audience was palpable.

Clearly, the issue of refereeing, which is all too often gatekeeping by other names, is one of intense interest to the membership of CELJ and academics in general at this time. Hence, the appropriateness of sponsoring a similar panel at the national MLA meeting in San Diego, and of publishing the proceedings of that panel in electronic form, in 1995.

Thus, I arrive at my conclusion to these brief introductory remarks. CELJ seeks to serve its membership (as of this writing 420 editors of scholarly journals around the world) first and foremost by providing them with up-todate and useful information. There are many means for providing this information -- MLA programs and regional MLA programs, for example; but as the 21st century approaches, the most important available means is clearly the computer and the Internet. We read today of computer monitors in cafes in the Bay Area where one can, for a quarter, access a few minutes of electronic mail time. We read that these monitors are replacing video games as the number one attraction in these cafes. We also read that the use of the Internet is increasing at a rate of $300,000 \%$ a year. These and similar data are perhaps factoids, but they are not to be ignored for all that. They suggest to anyone seriously interested in the fate of literacy in the age 
of computeracy that it is time to pay attention to the revolution already happening.

As CELJ thanks Surfaces for publishing its 1993 MLA program, we also recognize that such publication is but a necessary step in the direction of acknowledging the revolution for what it is and what it will be. This, then, is perhaps one small step for CELJ, but it is part of that giant step currently being taken by the post-industrial West in the direction of transforming our culture and our lives.

\section{R. A. Shoaf \\ President, CELJ (1994-1996) \\ EXEMPLA@nervm.nerdc.ufl.edu}

Surface Page d'Accueil/Home Page 